\title{
ENTRE LA ALUCINACIÓN Y LA REALIDAD: EL CASO 117.720 DE CARMEN NARANJO COTO
}

\author{
Mayela Vallejos Ramírez
}

\begin{abstract}
RESUMEN
El objetivo de este trabajo es hacer un acercamiento a la novela de Carmen Naranjo El caso 117.729. Esta extraordinaria novela nos plantea la situación de una sociedad que se está desintegrando, desvaneciendo, pudriéndose de la misma forma que lo está haciendo el protagonista de la novela quien padece de una enfermedad mental bastante extraña. El tratamiento de este tema social tan familiar es lo que hace singular la novela. Naranjo nos plantea una novela totalmente fragmentada curiosamente sin que se pierda el hilo conductor. La técnica, sin lugar a dudas, es de corte post-modernista. Palabras clave: irracionalidad, enfermedad, apariencia,cordura, locura.
\end{abstract}

\begin{abstract}
The main objective of this paper is to disentangle the essence of Carmen Naranjo's novel El caso 117.729. This extraordinary novel expounds the reality of a society that is disintegrating, vanishing, and rotting, similar to the main character of the novel. This man is fighting a terrible mental and physical illness that no doctor knows how to treat. The technique that the author uses to expose her points of view is what makes it very unique. The structure is fragmented; however, the plot does not lose its coherence.
\end{abstract}

Key words: irracionality, illness, appearence, common sense, madness.

Probablemente una de las novelas menos estudiada Carmen Naranjo sea $\mathrm{El}$ caso 117.729, publicada en 1987. En una segunda relectura, y digo segunda relectura porque en 1991 la trabajé como parte de mi tesis de maestría, he encontrado aspectos fascinantes que me han permitido un acercamiento de carácter posmodernista. La fragmentación del texto hace de la estructura una urdimbre de historias entrecruzadas que van uniendo los diferentes eventos ocurridos antes y después de la enfermedad de Antonio, personaje central alrededor de quien se desarrolla la trama. Este personaje se encuentra postrado en una cama, con una enfermedad

Ph.D. Mayela Vallejos Ramírez. Mesa State College, Department of Languages, English and Communication, Estados Unidos.

Correo electrónico: mvallejo@mesastate.edu

Recepción: 23- 4- 2009

Aceptación: 7- 5- 2009 
incurable e imposible de diagnosticar, como tan "claramente" lo expone el médico al iniciarse la narración. Digo claramente entre comillas porque, en esencia, lo que hace el médico es utilizar un discurso confuso, técnico y rebuscado para explicar lo inexplicable:

\footnotetext{
El caso es interesante, por lo general lo son, sobre todo si uno piensa en los síntomas y en las circunstancias. El diagnóstico puede ser cualquier nombre, es más se podría atener a los resultados del último encefalograma. La punción lumbar ha sido muy indicativa y los exámenes de sangre demuestran que la normalidad también da sorpresas (Naranjo 1987: 9).
}

Nótese que las palabras son huecas y sin sentido. La enfermedad puede ser cualquier padecimiento. El médico no tiene ninguna intensión de dejarnos saber nada en claro. Todos sus comentarios solo están orientados a convencer al lector de que el caso no es sencillo y se ha hecho lo posible por descifrar el enigma que encierra esta peculiar enfermedad, sin tener resultados precisos.

Al final, este es un caso más para los médicos. El estudio del paciente como un ser individual y personalizado se ha perdido completamente, para convertirse en un número más de los tantos casos que no tienen explicaciones lógicas: "Eso es todo lo que podemos hacer con el caso 117.720, un expediente completo para el estudio de futuros científicos" (1987: 13). El médico se muestra incapaz de resolverlo y, en vez de admitirlo, lo presenta como que servirá a la ciencia médica en el futuro, pero la verdad no sabe de lo que está hablando o si alguna vez alguien podría descifrar la enfermedad. Por lo tanto, escribir sobre El caso 117.729 es traspasar los límites de la cordura para enfrentarnos a un texto que plantea la racionalidad con base en la irracionalidad.

Esta novela está constituida por diecinueve capítulos; cada uno se encuentra fragmentado en situaciones, monólogos interiores, conversaciones, llamadas telefónicas, recuerdos y opiniones personales que se intercalan con las intromisiones acertadísimas del narrador en tercera persona. Los comentarios de esta voz narratológica hacen planteamientos filosóficos o comentarios relacionados con lo expresado por las otras personas. En otras palabras, el narrador comenta sobre lo que se oculta en las palabras que se expresan libremente, sin tener en cuenta lo oculto tras ellas.

Para clarificar lo anteriormente dicho citaremos las frases de aliento que le da una amiga a la madre del enfermo:

\footnotetext{
- No hay que desesperarse, la solución aparece cuando menos se piense. Con mamá y mis hermanas estamos haciendo una novena por su salud... Ya verás. En todo caso, lo tenemos muy adentro, cuenten con nosotros y si en algo les podemos ayudar...(1987: 39).
}

A estas palabras, el narrador comenta lo siguiente: “¿En que momento empieza el plural? ¿En qué momento no soy yo sino nosotros? ¿En qué instante desaparece el otro sustituidos por los otros y no se habla al otro sino a los otros? Las sumas exigen computadores electrónicos, la humanidad se filtra por los teléfonos" (1987: 39). Es interesante esta acotación porque es típico de los seres humanos involucrar a otros en nuestros propios compromisos morales y sociales; son frases que las hacemos para salir del compromiso, sobre todo cuando no se tiene nada más que decir, pero no queremos parecer insensibles ante el dolor ajeno. Estas notas del narrador dan al texto un tono irónico porque realzan, en muchos casos, la hipocresía de las personas y por ende de la sociedad.

Este narrador se convierte en un "metasujeto" si se toman en cuenta las apreciaciones hechas por Jean-Francois Lyotard, donde indica que en el texto postmoderno: "The narrador must be a metasubject in the process of formulating both the legitimacy of the discourse of the 
empirical science and that of the direct institution of popular culture" (1984:34). Por lo tanto, el narrador en este texto juega un papel fundamental, porque sus opiniones o planteamientos filosóficos están legitimando no solamente el discurso médico, que es el oficial, sino también el discurso popular dado por el conjunto de individuos que tienen algún tipo de opinión sobre el padecimiento de Antonio o su vida en general.

Este discurso popular se presenta de una manera totalmente fragmentada. Hay una discontinuidad narrativa, la cual obliga al lector a atar todos los cabos sueltos que se encuentran dispersos por todo el texto; como todo argumento postmoderno, se crea un collage de diferentes materiales. Las conversaciones entre los diferentes miembros de la familia no solo nos permiten aprender sobre la vida de Antonio y las posibles causas de su enfermedad, sino también nos dejan ver claramente el tipo de ser humano que es cada uno de ellos.

Por ejemplo, nos encontramos frente a una madre aterrorizada ante la situación de su hijo, pretendiendo darle el amor que nunca le dio antes: "Alguien gime a mi orilla. Esos ojos me recuerdan a mi madre. Ella no es, ella no hubiera tenido tiempo para gemir. Siempre algo detrás la retenía. Un niño que nace, un hombre que espera" (1987:131). Es una mujer que ha vivido una vida despreocupada, interesada nada más que en su propio bienestar. Aprendemos, por voces exteriores, que la mujer ha tenido tres matrimonios y Antonio es hijo de su primer matrimonio; ahora, angustiada, trata de calmar su conciencia con misas, novenas y contribuciones a la iglesia. Esto conlleva, por supuesto, una severa crítica de la religión desde dos perspectivas; por una parte, se critica la fe basada en la necesidad, así, la encontramos queriendo encontrar el alivio de su hijo en oraciones fervorosas que nunca antes había hecho: "Nunca he pedido con tanta fe..." (1987: 45). Pero la fe más bien aquí tiene una perspectiva mercantilista. Por otra parte, se critica a los representantes de la iglesia que tratan de sacarle provecho a este tipo de situaciones:

Orar es un acto de paciencia y humildad. Como usted sabe estamos construyendo una casa comunal y las personas organizadoras han pensado en usted... La fe debe ser siempre el apoyo de nuestras acciones. Le decía se ha considerado que usted podría contribuir... (1987: 45).

La manipulación de las palabras ejercidas por este representante de Dios muestran un claro cinismo; él realmente no está interesado en la situación de esta mujer y mucho menos en la curación de Antonio. Lo que verdaderamente está tratando de encontrar es la forma de como canjear la curación del joven por una cuantiosa donación. Esta mujer es probablemente la más afectada emocionalmente; de ahí, que no pueda ver la manipulación que se desarrolla a su alrededor por parte de los otros miembros de la familia con relación a la fortuna de Antonio. Su marido está preocupado por la posibilidad de que la ex esposa de Antonio se quede con una gran parte de los bienes; por supuesto, se justifica diciendo que lo único que le interesa es el bienestar de su mujer, quien no podría sobrevivir con menos porque está acostumbrada a demasiados lujos: "Y Dios sabe que lo único que me preocupa es la seguridad de ella. Yo tengo mi profesión y sólo me afectaré por los problemas que sufrirá la pobre" (1987: 83). El descaro de este hombre es absoluto.

Así mismo, aprendemos que las hermanas mayores de Antonio viven vidas muy distintas y distantes. Margarita, está casada con un diplomático y vive fuera del país, alejada de todo y de todos, la única relación estrecha que ha tenido en la vida la tuvo con Antonio. Esta ha sido un enigma para todos, porque nadie sabe qué secretos compartían, porque ni siquiera se pueden encontrar rastros de la correspondencia que mantenían. Lucrecia, por su parte, vive 
un mundo ilusorio basado en sus teorías de la metaficción, ella cree que Antonio no era de este mundo y ahora está depurando su cuerpo para encontrar la inmortalidad.

A la ex esposa de Antonio solo le preocupa heredar toda la fortuna que le sea posible, guardar las apariencias para mientras muere Antonio y así poder rehacer su vida con Juan, quien no está realmente interesado en casarse con ella, pues Juan se encuentra locamente enamorado de otra mujer, y solo trata de encontrar el momento preciso para darle la noticia: "En el último mes nuestra relación casi se ha reducido a llamadas telefónicas larguísimas y aburridas. Me limito a darle consejos para que asegure su porvenir" (1987: 90).

A estos cortes telenovelescos se unen los comentarios perversos de los vecinos, que han armando todo un circo alrededor de esta situación. Aquí, se puede apreciar la vileza del ser humano que se complace en la desgracia de los demás:

Tal vez sea algo peor... usted sabe esas enfermedades de la sangre... Vergüenza les debería de dar, ahí tiene los resultados de tanta cochinada que han hecho, Son bien sucios, aun cuando perfuman sus porquerías (1987:30).

Obsérvese, que estos comentarios llevan implícita la envidia, si bien puede ser cierto que esas personas no llevaban una vida tan honesta; la crítica deja ver el deseo tener aunque sea parte de la misma porquería. Otros planteamientos de esta índole están expresados por niños que realmente traslucen una extensión de la ideología familiar, actitud con la cual se van creando seres mezquinos, parte de una sociedad decadente y en retroceso.

La enfermedad de Antonio es muy significativa porque refleja la podredumbre que rodea a los seres humanos. La sociedad ha sufrido un profundo resquebrajamiento moral: la honestidad, la honradez, la lealtad y hasta el verdadero amor han desaparecido de él. Razón por la cual la relación familiar es duramente criticada. Los matrimonios son un fraude, una pantalla, un conjunto de infidelidades, un acomodo de conveniencias.

Al finalizar el texto, nos hallamos con un último diagnóstico médico que justifica la muerte del sujeto. Este último discurso con el cual se concluye la narración tiene las sutilísimas intromisiones del narrador omnisciente, para darle ese sentimiento un tanto mordaz. La causa de la enfermedad ha sido toda su vida. No hay explicaciones genéticas o fisiológicas reales. Este individuo nació predestinado para sufrir esta terrible enfermedad. La sintomatología que padeció al final no fue nada más que el resultado de toda una vida hueca y vacía. Así que: "El caso 117.720 (¿Podría ser la cábala de un número?) ya está claro y su claridad es sencilla como todas las claridades (lo profundo fue el mejor invento del miope). ¿Alguna duda?” (1987: 155).

La crítica que se da al lenguaje oficial es muy perspicaz. Los argumentos usados nuevamente por el médico son incompresibles; sin embargo, son aceptados por el grupo en general que quiere continuar dentro de un mundo evasivo que se esconde en palabras al parecer profundas, pero que en la realidad son incongruentes porque "lo profundo fue el mejor invento del miope" (1987: 155). El sutil sarcasmo del narrador deja ver una sociedad muerta porque donde no hay conocimiento no puede existir vida.

La aparente objetividad con la que se ha manejado el caso de este singular paciente nos lleva a incursionar, por último, en el paciente mismo. Antonio es la otra voz narrativa del texto, este es el narrador en primera persona que, dentro de su irracionalidad, nos muestra su ser interior; desde este mundo, el personaje nos habla de sí mismo y, sobre todo, de Antonio como si fueran dos entidades diferentes: "Hablan siempre de un extraño al que no reconozco y al que ligan de una manera rara conmigo. Hablan de él y me miran, hablan de él y me tocan, 
hablan de él y me examinan" (1987: 33). El Antonio que alguna vez fue lo dejó abandonado en el mundo de la cordura, ahora él es un nuevo ser:

\footnotetext{
Nado en el absurdo. Sin salida, sé que hubo un tiempo diferente. Llegaba a las cosas y las cosas eran. Ahora soy sólo yo, extrañamente yo: un punto que ahora se puede extender entre las paredes de este cuarto. Podría no estar aquí, pero estoy para adquirir conciencia de la eternidad (1987:25).
}

Lo más irónico es que Antonio descubre lo absurdo, lo vacío, lo mediocre de la vida en ese estado de inconciencia. Este joven que prometía tanto en la sociedad se encuentra totalmente separado del mundo concreto que lo rodea. Ha pasado a vivir dentro de otra dimensión: "Por fin comprendí que eso era la vida. Un hueco en el vacío. Las manos tienen los huecos más infinitos del mundo. En ellos cabe todo. Más de lo que puede retener un hombre" (1987: 40). Estas divagaciones filosóficas de Antonio plantean que la vida es simple, somos los seres humanos los que creamos un mundo caótico con ella. Lythord afirma que hay una gran complejidad entre el hombre y la naturaleza (1987:11). Esa complejidad es la que Antonio ya no puede manejar. Desaparece como sujeto porque no existe comunicación entre él y el exterior. La pérdida de la memoria y conocimiento lo llevan a la muerte porque ya no tiene los mecanismos para acoplarse a las reglas del medio que lo rodean.

El cuerpo, explica Lyotard, es la caparazón del instrumento más complejo que el pensamiento humano; por lo tanto, si el cuerpo no trabaja apropiadamente, la función primordial del ser humano, que es el pensamiento, no puede actuar. Por esta razón, Antonio tiene que desaparecer al final, ayudado por las compasivas enfermeras, que cansadas de él le ayudan a morir.

En conclusión, El caso 117.720 es una novela bastante compleja por la estructura fragmentada y por las voces diseminadas a través de toda la trama. No es simplemente el contraste de dos mundos: cordura y locura; es más bien el punto de convergencia donde se enfrentan dos realidades, la que queremos ver y la que realmente existe. La opción, como un buen texto postmoderno la tiene el lector.

\section{Bibliografía}

Lyotard, Jean Francois. 1984. The Postmodern Condition: a report o $n$ Knowledge. Geoff Bennington and Brian Massumi (trads.). Minneapolis: University of Minnesota Press.

Naranjo Coto, Carmen. 1987. El caso 117.720. San José: Editorial Costa Rica. 
